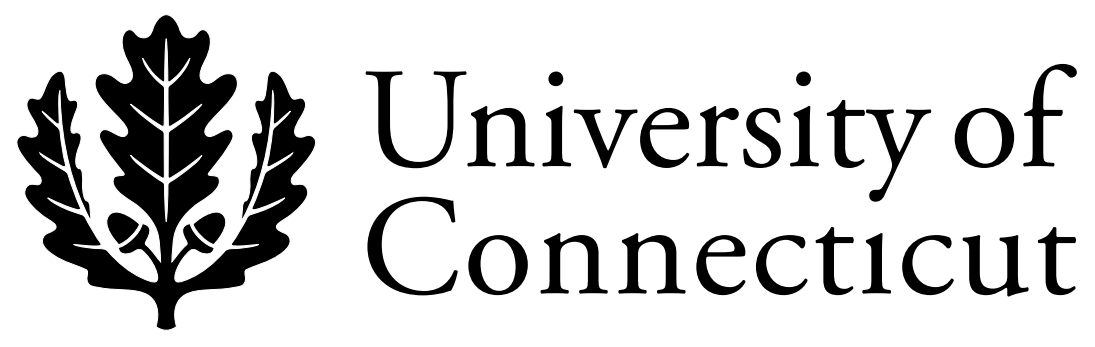

Department of Economics Working Paper Series

\title{
A Dynamic Stochastic Frontier Production Model with Time- Varying Efficiency
}

Evangelia Desli

Lloyds of London

Subhash C. Ray

University of Connecticut

Subal C. Kumbhakar

SUNY Binghampton

Working Paper 2003-15

September 2002

341 Mansfield Road, Unit 1063

Storrs, CT 06269-1063

Phone: (860) 486-3022

Fax: (860) 486-4463

http://www.econ.uconn.edu/ 


\begin{abstract}
In this paper we introduce technical efficiency via the intercept that evolve over time as a AR(1) process in a stochastic frontier (SF) framework in a panel data framework. Following are the distinguishing features of the model. First, the model is dynamic in nature. Second, it can separate technical inefficiency from fixed firm-specific effects which are not part of inefficiency. Third, the model allows one to estimate technical change separate from change in technical efficiency. We propose the ML method to estimate the parameters of the model. Finally, we derive expressions to calculate/predict technical inefficiency (efficiency).
\end{abstract}

Journal of Economic Literature Classification: C31 


\section{Introduction}

Although the importance of efficient use of resources has long been recognized, the mainstream neoclassical paradigm in economics assumes that producers in an economy always operate efficiently. In reality, however, the producers are not always efficient. Two otherwise identical firms never produce the same output, and costs and profit are not the same. This difference in output, cost, and profit can be explained in terms of efficiency, and some unforeseen exogenous shocks. Given the resources (inputs), a producer is said to be technically inefficient if it fails to produce the maximum possible output. Although several methods are available to measure inefficiency, our focus in this paper is on the stochastic frontier (SF) methodology developed by Aigner, Lovell and Schmidt (1977) and Meeusen and van den Broeck (1977). The SF methodology has subsequently been extended in many directions using both cross-sectional and panel data. In all these models the primary focus is on estimation of observation-specific efficiency.

One advantage of using panel data is that it gives an opportunity to examine and model behavior of technical efficiency over time. The earlier models (Pitt and Lee, 1980; Schmidt and Sickles, 1984; Kumbhakar, 1987; among others) treated technical efficiency as time invariant. Subsequent researchers allowed the technical efficiency to vary over time, but they model efficiency as a systematic function of time (Kumbhakar, 1990; Cornell, Schmidt and Sickles, 1990; Battese and Coelli, 1992; Lee and Schmidt, 1993). None of these models is formulated in a dynamic framework thereby meaning that an inefficient firm is not allowed to correct its inefficiency from the past. The problem with this approach is that, in most econometric models using time series data, technical change is also specified as an explicit function of time. As a result, one cannot distinguish between technical change and efficiency change in these models. 
This paper constructs a model specifying efficiency change through firm-specific intercept that evolves over time as a first order auto-regressive process (AR(1)). This is consistent with the belief that people learn from mistakes gradually. This approach builds on the CooleyPrescott (1973) adaptive regression model within the class of regression models with timevarying parameters. The estimating model is dynamic in nature. It allows efficiency in one period to be influenced by past levels of efficiency. Another feature of the model is that it permits separating technical efficiency from technical change.

\section{The Model}

Consider a panel data for $N$ firms observed over $T$ periods. Let $y_{i t}$ and $x_{i t}$ represent, respectively, the logarithms of a scalar output level and the input vector of $k$ inputs for firm $i$ at time $t$. The production function is specified as:

$$
y_{i t}=\alpha_{i t}+x_{i t} \beta+v_{i t} \text {, }
$$

where $v_{i t}$ is the error term that represents random shocks, $\beta$ is the vector of $k$ parameters for the input vector. The firm and time specific intercept, $\alpha_{i t}$, is a function of a firm specific intercepts $\left(\alpha_{i}\right)$, systematic factors that might persistently influence the firm's productivity and the position of the firm's production frontier over time $\left(w_{i t}\right)$. Random factors relating to technical inefficiency are modeled as a one-sided error term $\left(u_{i t}\right)$. The firm specific intercept is assumed to systematically evolve over time as an autoregressive (AR(1)) process:

$$
\alpha_{\text {it }}=\alpha_{i}+\phi \alpha_{i, t-1}+w_{i t} \gamma-u_{i t} ; u_{i t} \geq 0 \text {. }
$$

Since technical inefficiency is introduced into the model through the intercept and not as a deterministic function of time, we can include time as one of the explanatory variables in the vector $x_{i t}$. This allows us to distinguish between technical change and efficiency change. The above model can rewritten as 


$$
\begin{aligned}
& y_{i t}=\alpha_{i}+\phi y_{i, t-1}+x_{i t} \beta-x_{i, t-1} \phi \beta+w_{i t} \gamma+\varepsilon_{i t}, \\
& \text { where } \varepsilon_{\mathrm{it}}=\left(v_{i t}-\phi v_{i, t-1}\right)-u_{i t} ; \quad u_{i t} \geq 0 .
\end{aligned}
$$

The composed error term $\varepsilon$ in (3) has one component $\left(v_{i t}-\phi v_{i, t-1}\right)$ that follows an MA(1) process that is two sided $(-\infty,+\infty)$ and the other component $\left(u_{i t}\right)$ is one-sided $(0,+\infty)$.

Technical inefficiency of a firm $i$ at time $t$ is measured by $u_{i t}=y_{i t}^{f}-y_{i t}$ (i.e., the deviation of the observed output, $y_{i t}$, from the maximal producible output $\left(y_{i t}^{f}\right)$ given by

$$
y_{i t}^{f}=\alpha_{i}+\phi y_{i, t-1}+x_{i t} \beta-x_{i, t-1} \phi \beta+w_{i t} \gamma
$$

Technical efficiency (TE) is measured by

$$
T E_{i t}=e^{y_{i t}-y_{i t}^{f}}=e^{-u_{i t}} .
$$

The model in (3) has three distinguishing features that separate it from the existing panel data models. First, the model is dynamic in the sense that lagged value of $y$ appears as a regressor. Thus, past history of inefficiency affects present output. This, to our knowledge, is not used in stochastic frontier models. Second, technical inefficiency is separated from time-invariant firm-effect $\left(\alpha_{i}\right)$. Some of the earlier SF models treat firm-effects as time-invariant technical efficiency. Third, if time is introduced as a regressor in (3) via $w_{i t}$, we can estimate technical change (exogenous) from $\partial y / \partial t$. And we can separate technical change from technical efficiency, change defined as $\mathrm{TE}_{i t}-\mathrm{TE}_{i, t-1}$.

\section{Estimation of the Model:}

For estimation of the model and the corresponding measure of technical efficiency we make the usual assumption that $v_{i t}$ has the normal distribution while $\mathrm{u}_{\mathrm{it}}$ has the truncated normal distribution (truncated at zero from below). That is, 


$$
\mathrm{v}_{\mathrm{it}} \sim N\left(0, \sigma_{v}^{2}\right) \text { and } \mathrm{u}_{\mathrm{it}} \sim\left|N\left(0, \sigma_{u}^{2}\right)\right|, \mathrm{u}_{\mathrm{it}} \geq 0 .
$$

Define the vector $z_{i}=\left(z_{i 1}, z_{i 2}, \ldots, z_{i T}\right)^{\prime}$, where $z_{i t}=v_{i t}-\phi v_{i, t-1}$. Then, $z_{i} \sim N\left(0, \sigma_{v}^{2} \Omega\right)$

where $\Omega=\left[\begin{array}{llll}1+\phi^{2} & -\phi & \mathrm{K} & 0 \\ -\phi & 1+\phi^{2} & \mathrm{~K} & \mathrm{M} \\ \mathrm{M} & \mathrm{M} & \mathrm{O} & -\phi \\ 0 & 0 & -\phi & 1+\phi^{2}\end{array}\right]: \mathrm{T} \times \mathrm{T}$.

Thus the joint density function of $z_{i}$ is

$$
f\left(z_{i}\right)=\frac{1}{(2 \pi)^{T / 2}\left(\sigma_{v}^{2}\right)^{T / 2}|\Omega|^{1 / 2}} \exp \left\{-\frac{1}{2 \sigma_{v}^{2}} z_{i}{ }^{\prime} \Omega^{-1} z_{i}\right\} ; \quad z_{i} \in(-\infty, \infty)
$$

On the other hand, the one-sided disturbance vector

$$
\begin{aligned}
& \mathrm{u}_{\mathrm{i}}=\left(\mathrm{u}_{\mathrm{i} 1}, \mathrm{u}_{\mathrm{i} 2}, \ldots, \mathrm{u}_{\mathrm{iT}}\right)^{\prime} \sim\left|\mathrm{N}\left(0, \sigma_{\mathrm{u}}^{2} \mathrm{I}\right)\right| \text { has the joint density function } \\
& \mathrm{f}\left(\mathrm{u}_{\mathrm{i}}\right)=\frac{2^{\mathrm{T}}}{(2 \pi)^{\mathrm{T} / 2}\left(\sigma_{\mathrm{u}}^{2}\right)^{\mathrm{T} / 2}} \exp \left\{-\frac{1}{2 \sigma_{\mathrm{u}}^{2}} \mathrm{u}_{\mathrm{i}}{ }^{\prime} \mathrm{u}_{\mathrm{i}}\right\} ; \mathrm{u}_{\mathrm{i}} \geq 0
\end{aligned}
$$

Because $u_{i t}$ and $v_{i t}$ are independently distributed, the joint density of $\left(\varepsilon_{i}, u_{i}\right)$ can be expressed as

$$
\begin{gathered}
f\left(\varepsilon_{i}, u_{i}\right)=\frac{2^{T}}{(2 \pi)^{T}\left(\sigma_{v}^{2} \sigma_{u}^{2}\right)^{T / 2}|\Omega|^{1 / 2}} \exp \left\{-\frac{1}{2} \varepsilon_{i}^{\prime}\left[\sigma_{u}^{2} I+\sigma_{v}^{2} \Omega\right] \varepsilon_{i}\right\} \\
\times \exp \left\{-\frac{1}{2}\left(u_{i}+P \varepsilon_{i}\right)^{\prime}\left(\sigma_{u}^{2} \sigma_{v}^{2} \Omega\right)^{-1}\left[\sigma_{u}^{2} I+\sigma_{v}^{2} \Omega\right]\left(u_{i}+P \varepsilon_{i}\right)\right\} \\
\mathrm{u}_{i} \geq 0, \varepsilon_{\mathrm{i}} \in(-\infty, \infty)
\end{gathered}
$$

where $P=\sigma_{u}^{2}\left(\sigma_{u}^{2} I+\sigma_{v}^{2} \Omega\right)^{-1}$

and $\varepsilon_{\mathrm{i}}=\mathrm{z}_{\mathrm{i}}-\mathrm{u}_{\mathrm{i}}=\left(\varepsilon_{\mathrm{i} 1}, \varepsilon_{\mathrm{i} 2}, \ldots, \varepsilon_{\mathrm{iT}}\right)^{\prime}$.

The pdf of $\varepsilon_{\mathrm{i}}=\left(\varepsilon_{\mathrm{i} 1}, \varepsilon_{\mathrm{i} 2}, \ldots, \varepsilon_{\mathrm{iT}}\right)^{\prime}, f\left(\varepsilon_{i}\right)$ can then be derived by integrating $u$ out from (10), viz., 


$$
f\left(\varepsilon_{i}\right)=\frac{2^{T}\left[1-\Phi\left(Q \varepsilon_{i}\right)\right]}{(2 \pi)^{T / 2}\left|\sigma_{u}^{2} I+\sigma_{v}^{2} \Omega\right|^{1 / 2}} \exp \left\{-\frac{1}{2} \varepsilon_{i}^{\prime}\left[\sigma_{u}^{2} I+\sigma_{v}^{2} \Omega\right]^{-1} \varepsilon_{i}\right\},
$$

where

$$
\mathrm{Q}=\frac{\sigma_{\mathrm{u}}}{\sigma_{\mathrm{v}}}\left[\sigma_{\mathrm{u}}^{2} \mathrm{I}+\sigma_{\mathrm{v}}^{2} \Omega\right]^{-1 / 2} \Omega^{-1 / 2}
$$

and $\Omega$ is the variance-covariance matrix of the two-sided error term $v$, defined in (7).

The log-likelihood function for a sample of $N$ observations over $T$ periods is

$$
\begin{aligned}
& \ln L=N T \ln 2-\frac{N T}{2} \ln (2 \pi)-\frac{N T}{2} \ln \left(\left|\sigma_{u}^{2} I+\sigma_{v}^{2} \Omega\right|\right) \\
& +\sum_{i=1}^{N} \ln \left[1-\Phi\left(Q \varepsilon_{i}\right)\right]-\frac{1}{2} \sum_{i=1}^{N} \varepsilon_{i}^{\prime}\left[\sigma_{u}^{2} I+\sigma_{v}^{2} \Omega\right]^{-1} \varepsilon_{i}
\end{aligned}
$$

where $\varepsilon_{\text {it }}=y_{i t}-\phi y_{i, t-1}-\alpha_{i}-\left(x_{i t}-\phi x_{i, t-1}\right) \beta-w_{i t} \gamma$.

The above log-likelihood function can be maximized to obtain ML estimates of all the parameters.

\section{Estimation of Technical Efficiency:}

Now we consider estimation technical efficiency for each observation. For this we note that the distribution of $\mathrm{u}_{i} \mid \varepsilon_{i} \sim \mathrm{N}\left(\mu_{\mathrm{i}}, \Sigma\right)$ is truncated at zero from below. That is,

$$
\begin{gathered}
f\left(u_{i} \mid \varepsilon_{i}\right)=\frac{1}{(2 \pi)^{T / 2}|\Sigma|^{1 / 2}} \frac{1}{\left[1-\Phi\left(-\Sigma^{-1 / 2} \mu_{i}\right)\right]} \exp \left\{-\frac{1}{2}\left(u_{i}-\mu_{i}\right)^{\prime} \Sigma^{-1}\left(u_{i}-\mu_{i}\right)\right\}, \quad u_{i} \geq 0 \\
\text { where } \mu_{\mathrm{i}}=-\Sigma\left(\sigma_{\mathrm{v}}^{2} \Omega\right)^{-1} \varepsilon_{\mathrm{i}} \text { and } \Sigma=\left(\sigma_{u}^{2} \sigma_{v}^{2} \Omega\right)\left[\sigma_{u}^{2} I+\sigma_{v}^{2} \Omega\right]^{-1} .
\end{gathered}
$$

One can follow Jondrow et al. (1982) and Kumbhakar (1987) and estimate technical inefficiency, $u$ from either $E(u \mid \varepsilon)$ or $\operatorname{Mode}(u \mid \varepsilon)$ that can be calculated from (15). An alternative is to estimate technical efficiency from $E\left(e^{-u} \mid \varepsilon\right)$ (Battese and Coelli (1988)). 
We simplify these formulae below to obtain firm and time-specific measures of technical (in)efficiency.

Denote $u_{i}^{t}=\left(u_{i l}, u_{i 2}, \ldots, u_{i t}\right)$ and $\varepsilon_{i}^{t}=\left(\varepsilon_{i l}, \varepsilon_{i 2}, \ldots, \varepsilon_{i t}\right)$. Then using (15) we can write

$$
u_{i t} \mid\left(\varepsilon_{i}^{t}, u_{i}^{t-1}\right) \sim N\left(\mu_{i t}, \sigma_{t}^{2}\right)
$$

where

$$
\begin{aligned}
& \mu_{i t}=-\frac{\sigma_{u}^{2}}{\sigma_{v}^{2}+\sigma_{u}^{2} F_{t-1}^{2}}\left(F_{t-1}^{3}\left(\varepsilon_{i}^{t-1}+u_{i}^{t-1}\right)^{\prime}+\varepsilon_{i t} F_{t-1}^{2}\right) ; \\
& \sigma_{t}^{2}=\frac{\sigma_{v}^{2} \sigma_{u}^{2}}{\sigma_{v}^{2}+\sigma_{u}^{2} F_{t-1}^{2}} ; F_{t-1}^{2}=\frac{1-\phi^{2 t}}{1-\phi^{2(t+1)}} ; \\
& F_{t-1}^{3}=\left[f_{t-1}^{1}, f_{t-1}^{2}, \ldots, f_{t-1}^{t-1}\right]: 1 \times(\mathrm{t}-1) ; f_{t-1}^{i}=-\phi^{t-i} \frac{1-\phi^{2 i}}{1-\phi^{2(t+1)}} \text { for } 1 \leq \mathrm{i} \leq \mathrm{t}-1 .
\end{aligned}
$$

Using these results the Jondrow et al. (1982) formula for estimation technical inefficiency can be expressed as:

$$
\hat{u}_{i t}=E\left(u_{i t} \mid\left(\varepsilon_{i}^{t}, u_{i}^{t-1}\right)\right)=\mu_{i t}+\sigma_{t} \frac{\phi\left(\mu_{i t} / \sigma_{t}\right)}{\Phi\left(\mu_{i t} / \sigma_{t}\right)},
$$

where $\mu_{i t}$ and $\sigma_{t}$ are given in (18). The formula in (19) can be used to compute technical inefficiency for a firm $i$ at time $t$.

Similarly, the Battese-Coelli (1988) formula for technical efficiency becomes

$$
\hat{T} E_{i t}=E\left(e^{-u_{i t}} \mid \varepsilon_{i}^{t}, u_{i}^{t-1}\right)=e^{-\mu_{i t}+\sigma_{t}^{2} / 2} \times \frac{\left[1-\Phi\left(\sigma_{t}-\mu_{i t} / \sigma_{t}\right)\right]}{\left[1-\Phi\left(-\mu_{i t} / \sigma_{t}\right)\right]}
$$

This formula can be used to calculate technical efficiency for the $i$-th firm at time $t$. In practice the parameters in $\mu_{i t}$ and $\sigma_{t}$ are to be replaced by their estimated values.

Now we are examine the formulae in (19) and (20) in the light of those that are used to estimate technical (in)efficiency using panel data. First, note that prediction of (in)efficiency for firm $i$ at time $t$ will depend not only on $\varepsilon_{i t}$ but also on the its history of inefficiency up to 
time ( $t-1)$. Second, if $\phi=0$ then prediction of (in)efficiency for firm $i$ at time $t$ will depend only on $\varepsilon_{i t}$. The panel nature of the data will still be preserved because the model allows fixed firm-effects $\left(\alpha_{i}\right)$. But the model ceases to be dynamic. On the other hand, if $\phi=0$ and $\alpha_{i}=\alpha$ then the model fails to use the panel nature of the data in the sense that the model is no different from a cross-sectional model.

After estimating efficiency from (20) one can easily compute change in technical efficiency $(\triangle T E)$ from $\Delta T E=\hat{T} E_{i t}-\hat{T} E_{i, t-1}$. Similarly, change in technical inefficiency can be computed from $\hat{u}_{i t}-\hat{u}_{i, t-1}$ using (19). Finally, technical change can be estimated from $\partial y / \partial t$

\section{Conclusions}

This paper introduced a dyanmic stochastic frontier (SF) model in which technical efficiency is introduced via firm- and time-specific intercept that evolve over time as a AR(1) process. The model is formulated in a panel data framework. The model has some distinguishing features that make it unique among the SF panel models. First, the model is dynamic in nature and shows how technical efficiency evolves over time. Second, it separates technical inefficiency from fixed firm-specific effects that are not treated as parts of technical efficiency. Finally, the model generates technical change that are separated from change in technical efficiency. The ML method is developed to estimate the parameters of the model. Finally, we derive expressions to calculate both technical inefficiency and efficiency for each firm at every time period. 


\section{References:}

1. Aigner, D. J., Lovell, C. A. K. and Schmidt, P. (1977). Formulation and Estimation of Stochastic Frontier Production Function Models, Journal of Econometrics, 6, pp. 21-37.

2. Battese, G. E., and Coelli, T. J. (1988) Prediction of Firm-Level Technical Efficiencies with a Generalized Frontier Production Function and Panel Data, Journal of Econometrics 38, pp. 387-99.

3. Battese, G. E., and Coelli, T. J. (1992) Frontier Production Functions, Technical Efficiency and Panel Data: With Application to Paddy Farmers in India, Journal of Productivity Analysis 3:1/2 (June), pp. 153-69.

4. Cooley, T.F. and Prescott, E. (1973) An Adaptive Regression Model, International Economic Review, 14, pp. 364-371.

5. Cornwell, C., Schmidt, P. and Sickles, R. C. (1990) Production Frontiers with CrossSectional and Time-Series Variation in Efficiency Levels, Journal of Econometrics 46, pp. $185-200$.

6. Jondrow, J., Lovell, C. A. K., Materov, I. S. and Schmidt, P. (1982) On the Estimation of Technical Inefficiency in the Stochastic Frontier Production Function Model, Journal of Econometrics 19, pp. 233-38.

7. Kumbhakar, S. C. (1987) The Specification of Technical and Allocative Inefficiency in Stochastic Production and Profit Frontiers, Journal of Econometrics 34, pp. 335-48.

8. Kumbhakar, S. C. (1990) Production Frontiers, Panel Data, and Time-Varying Technical Inefficiency, Journal of Econometrics 46, pp. 201-12.

9. Lee, Y. H., and Schmidt, P. (1993) A Production Frontier Model with Flexible Temporal Variation in Technical Inefficiency, in The Measurement of Productive Efficiency: Techniques and Applications (Ed.) H. O. Fried, C. A. K. Lovell and S. S. Schmidt, Oxford University Press, New York. 
10. Meeusen, W., and van den Broeck, J. (1977) Efficiency Estimation from Cobb-Douglas Production Functions with Composed Error, International Economic Review 18, pp. 43544.

11. Pitt, M., and Lee, L. F. (1981) The Measurement and Sources of Technical Inefficiency in the Indonesian Weaving Industry, Journal of Development Economics 9, pp. 43-64.

12. Schmidt, P., and Sickles, R. C. (1984) Production Frontiers and Panel Data, Journal of Business and Economic Statistics 2, pp. 367-74. 